\title{
A short - time effect of one-session application of Proprioceptive Neuromuscular Facilitation (PNF) bilateral leg pattern used with contract relax technique and asymmetrical breathing in girls with Adolescent Idiopathic Scoliosis (AIS)
}

\author{
Stępień Agnieszka* ${ }^{*}$, Graff Krzysztof ${ }^{1}$, Podgurniak Małgorzata² \\ From 11th International Conference on Conservative Management of Spinal Deformities - SOSORT 2014 \\ Annual Meeting \\ Wiesbaden, Germany. 8-10 May 2014
}

\section{Background}

Physiotherapy is a part of conservative scoliosis treatment [1]. Different theories, methods and exercises was proposed and used to date, but only a few of them was proved and recognized as effective. PNF is one of methods in physiotherapy used in orthopedic and neurological diseases [2]. PNF philosophy, three- dimensional patterns, techniques, breathing and movement stimulation can be useful in AIS therapy. Recent author's studies established limited range of trunk and pelvis rotation (TPR) in AIS girls with double curve scoliosis [3].

\section{Aim}

The aim of the study was to estimate a short time effect of one- session application of PNF bilateral leg patterns used with Contract - Relax technique and asymmetrical breathing on the angle of trunk rotation (ATR) and TPR in AIS girls.

\section{Design}

Case series.

\section{Methods}

25 girls $(12,2)$ with double curve scoliosis participated in the study. The right thoracic curve $(28,1)$ and the left lumbar curve $(24,6)$ at the spine radiography were including criteria. The clinical assessment, performed before and after therapy, comprised the Angle of Trunk Rotation (ATR) and an original test - Trunk/Pelvis/Hip Angle test (TPHA) created to evaluate TPR. PNF bilateral leg pattern, applied in the supine position with the thorax stabilization, combined with Contract Relax technique and asymmetrical breathing, was used to improve range of rotation into the direction of limitation. To determine statistical differences paired t-test/sign test/ signed range test and two samples t-test/Mann-Whitney (Wilcoxon) were used.

\section{Results}

Significant difference between right and left TPR was observed before treatment in AIS girls $(\mathrm{p}<0,001)$. There was no significant difference TPR after therapy. ATR values were significant lower after therapy - ATR Th $(\mathrm{p}<0,001)$, ATR L $(\mathrm{p}<0,01)$.

\section{Conclusion}

PNF bilateral leg pattern used with Contract Relax technique and asymmetrical breathing influence ATR and TPR in AIS girls. There is necessary to continue study in numerous AIS group with different types of spine deformation.

\section{Authors' details \\ ${ }^{1}$ Józef Piłsudski University of Physical Education, Warsaw, Poland. ${ }^{2}$ Warsaw University of Life Science, Warsaw, Poland.}

1Józef Piłsudski University of Physical Education, Warsaw, Poland Full list of author information is available at the end of the article 


\section{References}

1. Weiss HR, Negrini S, Rigo M, Kotwicki T, Hawes MC, Grivas TB, Maruyama T, Landauer F: SOSORT guideline committee: Indications for conservative management of scoliosis (guidelines). Scoliosis 2006, 1:5.

2. Adler S, Beckers D, Buck M: PNF in Practice. Springer Verlag Berlin Heidelberg; 2014.

3. Stępien $A$, Seyfried $A$ : The range of rotation of the trunk and pelvis in adolescent girls with idiopathic scoliosis. Advances in Rehabilitation 2011, 25(3):5-12.

doi:10.1186/1748-7161-9-S1-063

Cite this article as: Agnieszka et al:: A short - time effect of one-session application of Proprioceptive Neuromuscular Facilitation (PNF) bilateral leg pattern used with contract relax technique and asymmetrical breathing in girls with Adolescent Idiopathic Scoliosis (AIS). Scoliosis 2014 9(Suppl 1):063.

\section{Submit your next manuscript to BioMed Central} and take full advantage of:

- Convenient online submission

- Thorough peer review

- No space constraints or color figure charges

- Immediate publication on acceptance

- Inclusion in PubMed, CAS, Scopus and Google Scholar

- Research which is freely available for redistribution

Submit your manuscript at www.biomedcentral.com/submit
Ciomed Central 